\title{
EFFICIENCY ASSESSMENT OF CONTAINER OPERATIONS OF SHIPPING AGENTS IN SPANISH PORTS
}

\author{
E. Gutiérrez ${ }^{a \S}$, S. Lozano ${ }^{a}$, B. Adenso-Díaz ${ }^{b}$ and P. González-Torre ${ }^{b}$ \\ ${ }^{a}$ Escuela Técnica Superior de Ingenieros, Universidad de Sevilla, Spain \\ ${ }^{\mathrm{b}}$ Escuela Politécnica de Ingeniería de Gijón, Universidad de Oviedo, 33204 Gijón, Spain
}

\begin{abstract}
$\underline{\text { Abstract }}$
In this paper a two-stage Data Envelopment Approach (DEA) is used to assess the relative efficiency of container shipping agents operating in Spanish ports, studying also its influencing factors. In the first stage, an input-oriented, Variable Returns To Scale (VRS) model is used to compute efficiency scores of the different shipping agents. The model considers labor as input and numbers of loaded and unloaded containers handled as outputs. Scale efficiency, Returns to Scale and average efficiency of shipping agents in each port are reported. In the second stage, different regression approaches are applied to relate the efficiency scores obtained to a number of exogenous variables. The results identify as significant some of these variables such as the number of container lines with which it operates. Belonging to each of four clusters identified from the dataset seems also to have a significant influence on the efficiency of the studied agents.
\end{abstract}

Keywords: Maritime transport, shipping agents, efficiency, DEA, two-stage analysis

${ }^{\S}$ Corresponding author

Mail address: $\quad$ Ester Gutiérrez

Escuela Técnica Superior de Ingenieros

Camino de los Descubrimientos, s/n

41092 Sevilla, Spain

E-mail: egm@us.es

Phone: +34-954486198

Fax:+34-954487329 


\section{Introduction}

As globalization emerged in the international economy, maritime traffic has been increasing continuously in the last decades and its agents have internationalized its activity (Gadhia et al., 2011). The ports, that traditionally were simple points of transhipment between ships and land transportation (Mangan et al., 2008), have became in logistic platforms and in important clusters of economic activities (Thai, 2012) due to the fact they are indeed linkages between service providers, facilitators, operators and end customers (Pettit and Beresford, 2009).

Vessel size has increased dramatically in that period and fewer ports were able to handle larger vessels, concentrating this large maritime traffic in certain ports (Mangan et al., 2008). While global maritime freight has grown, there is an imbalanced traffic across different corridors, especially in the case of containerised traffic (Mangan et al., 2008). On the other hand, in the maritime shipping supply chain, the performance and coordination of four different players are required: ports, shippers, containers depots and shipping agents. In the literature review, several studies about the first three agents are found (Wang and Meng, 2012; Thai, 2012; Pallis et al., 2010; Benito et al., 2003). Regarding the shipping agents, they are the representatives of the shippers in the port, in charge of all the administrative and commercial tasks. Their activity increases the efficacy in the supply chain operations, as a result of their experience and know-how (Bichou, Bell, 2007). One possible way of measuring that efficacy is by assessing the service quality, the load/unload ratios, and handling costs, all of which serve as key factors for the selection of a specific shipping agent (Saeed, 2009). Their role is determinant also in the development of the short 
sea shipping and the sea motorways (Beškovnik, 2006). However, in spite of their importance in the efficient operation of maritime transportation, shipping agents have deserved limited attention from researchers, with just a few works dealing with that role (Saeed, 2009, González-Torre et al., 2013).

For our study we are going to focus on data coming from the Spanish ports. In the last 50 years, the million tonnes moved through its maritime port system was multiplied by 7 , reaching more than 400 millions tonnes per year. Furthermore, the Spanish shipping agents studied here handled an annual average of 16,886 exported TEU and 19,356 imported TEU. That national port system, composed of 28 ports, includes one of the most important Mediterranean hubs (Barcelona), the largest Mediterranean (and fifth in Europe) in container traffic (Valencia, with 3.7 million TEUs in 2009, out of the 7.7 millions of all Spain), or Bilbao, one of the most important transport and logistics centres in the European Atlantic Arc. For that reason, the Spanish shipping agents are mainly concentrated around these three ports. And although in most of cases the shipping agents belong to a multiorganisational business group, they are mainly small firms, which activity in the maritime industry began 30 years ago.

The motivation to use DEA in the present research is supported by DEA being a well established non-parametric frontier analysis technique, capable of evaluating the relative efficiency of a set of operating units (commonly termed Decision Making Units, DMU) with multiple inputs/outputs (for further details see, for example, Thanassoulis, 2001, Cooper et al., 2004, 2006, Zhu, 2002). DEA has been applied in many different industrial and service sectors, among them to maritime transport. Thus, the efficiency of both general 
ports and container terminal has been extensively studied (e.g. Tongzon, 2001, Barros and Athanassiou, 2004, Cullinane et al, 2006, Wang and Cullinane, 2006, Barros, 2006, Ríos and Maçada, 2006, Pallis and Syriopoulos, 2007, Kamble et al., 2010, Lin and Tseng, 2007, Hung et al., 2010, Wu and Goh, 2010, Cullinane and Wang, 2010). Special mention may be made to Bichou (2011) for it uses a network DEA approach for measuring container terminal efficiency. DEA has also been used to estimate the productivity growth of ports (e.g. Estache et al, 2004, Barros and Peypoch, 2007, Guironnet et al., 2009, Lozano, 2009, Haralambides et al, 2010, Barros et al., 2012) and of shipping companies (Managi, 2007, Gutiérrez et al., 2014) as well as for capital budgeting of ports (Lozano et al., 2011). However, probably because of data availability issues, the efficiency of shipping agents seems not to have been studied before. This is surprising given the importance of shipping agents as the agents of shipping companies at a port and, as such, responsible for the handling of the freight loaded and unloaded in that port.

In this paper the results of a study of 85 shipping agents operating in Spanish ports are presented. The data have been obtained through a survey of the companies. Details of the survey are reported in González-Torre et al. (2013) in which a clustering of the shipping agents has also been carried out. From the survey responses input and output data were selected for an efficiency assessment using DEA. Specifically a two-stage approach is used so that the efficiency scores obtained in stage one are regressed in stage two against some exogenous variables.

The structure of the paper is the following. In section 2 the stage one of the DEA approach and the corresponding relative efficiency results are presented. Section 3 presents the 
second stage of the analysis. Section 4 summarizes and concludes.

\section{Stage one: Efficiency scores of shipping agents}

To gather data for the analysis, we considered the census of all shipping agents listed in the documentation published by the Spanish Port Authorities (250 companies). During 2008, we carried out a survey in which 85 of these companies participated (among them 19 shipping agents from Valencia, 18 from Bilbao and 13 from Barcelona), which means a response rate of $34 \%$ and a sample error of $8.43 \%$ at a confidence level of $95 \%$.

The data collected from the survey and used to assess the efficiency of Spanish shipping agents are shown in Table 1. DEA models require the identification of inputs and outputs. Wang et al. (2005) discuss the variable definition for port efficiency estimation. They stated that port production depends on the efficiency use of labor, land and equipment. In our case, due to lack of direct information on port infrastructure/superstructure, only information on labor input has been considered (Notteboom et al. 2000). On the other hand, container throughput is a crucial factor for port management (Cullinane and Wang, 2006) since it is related to cargo-related services in the port, constituting the benchmark for comparing the port efficiency. Empty container throughput has also been included because empty container management is one of the sharpest problems suffering the logistics industry worldwide (e.g. Boile and Aboobaker, 2006; Sun and Yang, 2006). Hence, this study use a single input, namely number of employees, and two outputs that describe the container operations of shipping agents, namely the number of loaded and empty containers handled. Note that although some outputs are zero, this should pose no problem to DEA, 
provided no-radial output oriented models are avoided, as in our case. Of course, the radial efficiency score used does not include possible output slacks that may remain. This is a limitation of Farrell efficiency, which only guarantees weak efficiency but not ParetoKoopmans efficiency. An alternative, which we have not pursued, is to use for example the Measure of Efficiency Dominance as efficiency score (Bardhan et al., 1996).

Table 2 shows the technical efficiency scores of the different shipping agents computed using the well-known DEA-BCC model (Banker et al., 1984). Although other, more sophisticated DEA models (e.g. non-radial or slacks-based) could have been applied, the DEA-BCC model was chosen because is the simplest and still most widely used DEA approach. LINGO optimization software has been used. Since there may be scale effects and since there is no guarantee that the DMUs operate at their Most Productive Scale Size (Banker, 1984) Variable Returns to Scale (VRS) have been assumed. An input orientation has been chosen because it is assumed that shipping agent management has no control over outputs. As suggested by one of the reviewers, we have tested if the efficiency results obtained considering loaded and empty containers differ from the efficiency results integrating full and empty container in one single output. This would happen if a significantly different level of effort were needed by shipping agents in dealing with both types of containers. The results of the Mann-Whitney test (W statistic=7662.5; pvalue $=0.2188$ ) cannot reject the null hypothesis that the results of both DEA models come from a common efficiency distribution. Thus, the Pearson correlation coefficient of both sets of efficiency results is rather high (0.922). This suggests that there does not seem to be 
great differences in the effort levels in the administrative work required by empty and loaded containers and that similar results can be obtained considering a single, pooled output. This can be seen as a confirmation of the validity of the obtained efficiency results.

The application of the iterative procedure of Ahn Tran et al., (2010) has allowed the identification and removal of 8 outliers (namely DMUs 7, 11, 14, 38, 49, 61, 76 and 85) which leads to a reduced dataset of 77 DMUs. Table 3 shows the $\lambda$-sum and $\lambda$-count values corresponding to the DMU removed in each iteration of the Ahn Tran et al., (2010) method. Note that the removed DMUs had actually high values of both of these indicators and therefore can be identified as outliers. Note also that, after removing 8 DMUs, the maximum values of both indicators were much reduced and the process stopped.

The technical efficiency scores of the remaining DMUs as well as their corresponding Returns To Scale (Constant=CRS, Increasing=IRS or Decreasing=DRS) and the output slacks corresponding to the two outputs ( $\mathrm{LC}=$ Loaded Container, $\mathrm{EC}=$ Empty Container) are also shown in Table 2 .

In order to determine the Returns to Scale (RTS), the efficiency measures of DEA model can be calculated with different scale assumptions. Thus, the Scale Efficiency is just the 
ratio $S . E f f=\frac{T \cdot E f f^{\prime}{ }_{C R S}}{T . E f f^{\prime}{ }_{V R S}}$, where a value of $S . E f f=1$ indicates that a shipping agent is fully scale efficient and therefore exhibits CRS. On the other hand, a value of $S$. Eff $<1$ indicates that the shipping agent might be operating either in a region of IRS or DRS. To discriminate between those two cases the Non-Increasing returns to scale (NIRS) efficiency measure is computed so that if $T$. Eff $^{\prime}{ }_{C R S}=$ T.Eff $^{\prime}{ }_{\text {NIRS }}<T . E f f{ }^{\prime}{ }_{V R S}$ IRS prevail while if T.Eff ${ }_{C R S}<T . E f f{ }^{\prime}{ }_{\text {NIRS }}=T . E f f{ }^{\prime}{ }_{V R S}$ then the DMU exhibits DRS.

The slacks represent the feasible output increases that remain after the input reduction given by the efficiency scores. Note that only eight out of the 77 remaining shipping agents (shown in bold) are technically efficient and of those only two (in italics) are also scale efficient. One of the two global efficient shipping agents operates in Vigo and the other in Bilbao. Of the other six technically efficient shipping agents four (one in of the ports of Algeciras, Barcelona, Bilbao, Gijón and Las Palmas) exhibit Increasing Returns to Scale (IRS) and just one (operating in the port of Valencia) seems to exhibit Decreasing Returns to Scale (DRS). All the technically inefficient shipping agents exhibit IRS. It can therefore be concluded that the majority of shipping agents operating in Spanish ports have IRS, which means that they would benefit from a certain consolidation in the sector.

The distribution of the technical efficiency per port is shown in Figure 1. The corresponding box and whisker plots show the mean, median, minimum, and maximum values as well as the 25th and 75th percentiles (lower and upper quantile, respectively) for each port. The mean values of the technical efficiency for the three main ports (Barcelona, Bilbao and Valencia) are $0.35,0.39$, and 0.40 while for the other Spanish ports the median 
technical efficiency is 0.49 . Note that the main three Spanish ports have slightly lower technical efficiency than the Other Spanish ports. Moreover, the location of the median line suggests more skewness in the technical efficiency of Valencia than in Barcelona, Bilbao or Other ports. Three efficient shipping agents are identified as local outliers within the group of shipping agents in the ports of Barcelona (DMU 79) and Bilbao (DMUs 57 and 60), after screening the whole dataset for global outliers.

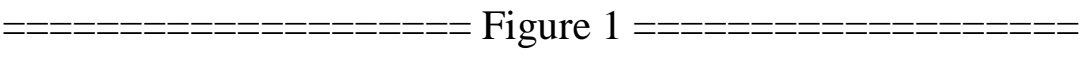

Finally, not only the efficiency scores have been computed but also target input values and peer groups. In total, around 1,000 employees may be redundant, which corresponds to around $60 \%$ of the current total. This gives an overall idea of the inefficiency level of the industry.

\section{Stage two: Influencing factors analysis}

In this section, a regression analysis of the technical efficiency scores of the different shipping agents is carried out using as explanatory variables whether the shipping agent is operating in one of the three main ports (dummy variables labeled Barcelona, Bilbao and Valencia) or in one of the other ports, the number of shipping companies (labeled ShipComp) and the number of container shipping lines with which it works (labeled ShipLines), and, finally, the cluster (as per González-Torre et al., 2013) to which the shipping agent can be assigned (dummy variables labeled $C 1, C 2$ and $C 3$ ). According to that study, shipping agents can be grouped in four clusters. Cluster 1 is the largest cluster, 
made up of firms specialized in nationally-focused container transportation, i.e. they are less import/export oriented. The typical shipping agent in this cluster has many years experience and have the largest value of the number of shippers with which they work. Cluster 2 shipping agents have the largest average number of employees. Much of their container traffic is at the regional level and they process a smaller number of ships. Cluster 3 is formed by shipping agents with the lowest number of years of operation. Although it is not the majority of their activity, they are the ones that handled more international container traffic. Shipping agents in Cluster 4 also have many shippers and a good number of years in operation but they have the lowest container traffic at all levels: international, national and regional.

These regression models aim at explaining the efficiency of shipping agents through their geographical location, number of clients (container shipping lines and shipping companies) and the classification of shipping agents. These variables have been chosen among those gathered in the survey of Spanish shipping agents (see González-Torre et al. 2013) because they may have an influence on the efficiency of the shipping agents, although the specific sign (positive or negative) of such influence is not known a priori. Table 4 presents the data used in the regression analysis of the shipping agents. Note that there are a few (exactly six) shipping agents that do not belong to any of the four clusters. That occurs because they are dissimilar to the other agents that belong to each cluster.

With respect to the specific regression approach to use, when dealing with efficiency 
measures, most researchers have used either Ordinary Least Squares (OLS) (e.g. Ataullah and Le 2006, Hwang and Kao 2008) or Tobit regression (e.g. Lansink and Reinhart 2004, Afonso and St. Aubyn 2006, Yeh et al 2010). Although some studies indicate that both approaches work similarly well (Hoff 2007, Banker and Natarajan 2008) there seems to be some advantages in using OLS over Tobit, due to Tobit estimation procedure providing inconsistent estimates (McDonald 2009, Estelle et al 2010). In this respect, different methodologies have been proposed in order to provide consistent inferences from the DEA model, such as Quasi-Maximum Likelihood Estimation (QLME) approach (Papke and Wooldridge 1996) and Truncated Bootstrapped Regression (TBR) (Simar and Wilson 2007).

In this paper we have used OLS as well as QMLE and TBR to regress the DEA scores on the explanatory variables. The specifications of the different models are shown in Table 5.

Linear regression was the first model specification considered, finding evidence to reject the normality of the efficiency scores at the 5\% significance level (Anderson Darling statistic $\mathrm{A}^{2}=1.480 ; \mathrm{p}$-value=0.005). As a remedial action to non-normality a proper BoxCox transformation ( $\lambda=0$, i.e. logarithmic transformation) was successfully applied. Table 6 shows the results of OLS, QLME and TBR. These results were obtained using R package (release 9) and Stata (release 11). Note that the estimated coefficients that are significant are the number of container shipping lines which the shipping agent works with, as well as, the dummy variables that correspond to the three clusters $(\mathrm{C} 1, \mathrm{C} 2$ and $\mathrm{C} 3)$. Nevertheless, 
C1, C2 and C3 have more impact than ShipLines. Moreover, all three models (1-3) agree in the sign of the influence of significant exogenous variables. Respect to OLS model, the overall significance of the OLS regression (model 1) passes the F test, indicating significant relationships between the efficiency score and the exogenous variables considered. In addition, residual analysis of model (1) satisfies independence assumption (Durbin-Watson statistic DW=2.4935, p-value 0.9745), and there is not statistical evidence of heteroscedasticity (Goldfeld-Quandt GQ statistic= 1.5829, p-value 0.1227).The functional form of the model (1) and model (2) were tested by computing Ramsey's RESET statistic without finding empirical evidence of misspecification in the models (Papke and Wooldridge 1996). A direct comparison of models (1), (2) and (3) from log-likelihood criterion, evidence that model (3) is the best for explaining the efficiency of the container operations of shipping agents in Spanish ports.

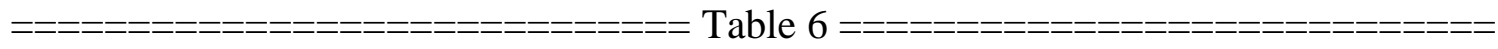

The estimated regression models indicate that the efficiency score is related to the clusters variables and to the number of container shipping lines. According to the three models, the variables indicating the clusters 1,2 and 3 are all significant with the coefficient of $\mathrm{C} 1$ larger than that of $\mathrm{C} 2$ and this larger than that of C3. Thus, for example, according to model (3), where the coefficients are corrected for bias, on average, the influence of cluster 1-3 is $0.36,0.22$ and 0.20 , respectively. This reveals to what extent the management practices of shipping agents belonging to the $\mathrm{C} 1$ contribute further to their efficient performance, probably due to their having a longer experience. 
On the other hand, the marginal effect in terms of the ShipLines over Efficiency is 0.0321, i.e., the mean technical efficiency can increase 0.0321 for every 1 -unit increase in number of shipping lines the shipping agent operates with. This variable turns out to have positive coefficient providing evidence of size of shipping line portfolio potentially affects efficiency. This increase in efficiency due to working with a larger number of shipping lines may be interpreted in the following way: shipping lines looking for a shipping agent to manage their local business will be inclined to contract those agents that are more efficient. It can also happen that the concentration of work from multiple shipping lines allows to these shipping agents obtain economies of scale that result in more efficient services.

In contrast, the geographical location of the port and number of shipping companies with which Spanish shipping agents work are insignificant in the three models. This is important to shipping agents in order to avoid support their performance strategy in location decisions, as well as the number of shipping companies they offer their services to.

To obtain additional insights into the efficiency of shipping agents, a regression model was estimated incorporating an additional dummy variable (labeled Delegation) to test whether the operating benefits of the shipping agents depend on its being a branch of a larger shipping agency company. The results confirmed those of Table 6, but the Delegation variable was statistically insignificant in the regression models (1-3) at the 0.10 level, remaining the sign of the significant variables the same. These findings provide evidence supporting the view that the shipping agents' efficiency is not influenced by its being, or not, a branch of a large shipping company. 


\section{Summary and conclusions}

In this paper a two-stage DEA study of the technical and scale efficiency of the shipping agents operating containers in Spanish ports is presented. After detecting and removing a few outliers, eight technical efficient and two global efficient shipping agents are identified. Overall efficiency levels are low with most companies employing a larger number of employees than required. The average efficiency of the shipping agents operating at each of the main ports has also been computed. Also, the efficiency of shipping agents belonging to each of the four clusters identified in the literature has been analysed.

Finally, in the second stage, technical efficiency scores have been regressed against a number of exogenous variables and a number of factors (e.g. number of associated container lines and cluster to which the agent belongs) have been found to be significant in explaining the observed efficiency scores. In particular, those shipping agents belonging to cluster 4 are less efficient than the rest while agents belonging to cluster 1 are more efficient than the rest.

Regarding the managerial implications of this research, we have provided clues to better understand what are the main factors affecting the technical efficiency of the shipping agents' operations, and therefore, what could be important when defining strategies for those firms. We have shown how inefficient is this industry overall, and have collected proofs supporting that consolidation in the sector could be advantageous for companies. 
Our results show that the number of container lines operated has a positive influence in the efficiency of the shipping agents, although possibly more as a consequence than as a cause. Both the experience curve effect and the economies of scale gained when working with so many lines could explain the relevance of this factor, while such benefits are not observed when working with many shippers. Finally, these companies, according to our results, would not obtain significant efficiency benefits due to relocating to bigger ports or for the fact of being a subsidiary of a shipper instead of an independent firm.

As for possible continuations of this research, one would be to include in the analysis not only the container processing activity but also their cargo freight business. It would also be interesting to extend the analysis to other countries and see if similar results are found. It would also help to benchmark the best practices of the different countries and test whether the regulatory environment has an influence.

\section{Acknowledgments}

The authors are grateful for the constructive comments and suggestions provided by anonymous reviewers. This research was carried out with the financial support of the Spanish Ministry of Science grant DPI2013-41469, and FEDER. We are also grateful to Professor Harald Oberhofer, University of Salzburg (Austria), who kindly provide us the Stata code for robust RESET test of fractional response model.

\section{References}

Anh Tran, N. Shively, G. and Preckel, P. (2010) “A new method for detecting outliers in Data Envelopment Analysis", Applied Economics Letters, 17, 4, 313-316 
Ataullah, A. and Le, H. (2006) "Economic reforms and bank efficiency in developing countries: the case of the Indian banking industry", Applied Financial Economics, 16, 653663

Afonso, A. and St. Aubyn, M. (2006) "Cross-country efficiency of secondary education provision: A semi-parametric analysis with non-discretionary inputs", Economic Modelling, $23,476-491$

Banker, R.D. (1984) "Estimating most productive scale size using data envelopment analysis", European Journal of Operational Research, 17, 35-44

Banker, R.D., Charnes, A. and Cooper, W.W. (1984) "Some Models for Estimating Technical and Scale Inefficiencies in Data Envelopment Analysis", Management Science, 30, 1078-1092

Banker, R.D. and Natarajan, R. (2008) "Evaluating Contextual Variables Affecting Productivity Using Data Envelopment Analysis”, Operations Research, 56, 1, 48-58

Bardhan I., Bowlin, W.F., Cooper, W.W. and Sueyoshi, T. (1996) "Models and measures for efficiency dominance in DEA. Part I: Additive models and MED measures", Journal of the Operations Research Society of Japan, 39, 3, 322-332

Barros, C.P. (2006) “A Benchmark Analysis of Italian Seaport Using Data Envelopment Analysis", Maritime Economics and Logistics, 8, 347-365

Barros, C.P. and Athanassiou, M. (2004) "Efficiency in European Seaports with DEA: Evidence from Greece and Portugal”, Maritime Economics and Logistics, 6, 122-140 
Barros, C.P. and Peypoch, N. (2007) "Comparing Productivity Change in Italian and Portuguese Seaports using Luenberger Indicator Approach", Maritime Economics and Logistics, 9, 138-147

Barros, C.P., Felício, J.A. and Fernandes, R.L. (2012) "Productivity analysis of Brazilian seaports", Maritime Policy and Management, 39, 503-523

Benito, G.R.G., Berger, E., de la Forest, M. and Shum, J. (2003) "A cluster analysis of the maritime sector in Norway", International Journal of Transport Management, 1, 203-215

Beskovnik, B. (2006) "Importance of short sea shipping and sea motorways in the European and Slovenian transport policy", Journal of Maritime Studies, 20, 1, 23-35.

Bichou, K. and Bell, M.G.H. (2007) "Internationalisation and consolidation of the container port industry: assessment of channel structure and relationships", Maritime Economics \& Logistics, 9, 35-51.

Bichou, K., (2011) "A two-stage supply chain DEA model for measuring containerterminal efficiency", International Journal of Shipping and Transport Logistics, 3, 1, 6-26

Boile, M.P. and Aboobaker, N. (2006) "Empty intermodal container management, NJDOT Project 2006-005, Final Report”. Department of Civil and Environmental Engineering Center for Infrastructure and Transportation (CAI), New Jersey

Cooper W.W, Seiford, L.M. and Tone, K., Data Envelopment Analysis: A Comprehensive Text with Models, Applications, References and DEA-Solver Software, $2^{\text {nd }}$ edition, Springer, New York, 2006 
Cooper W.W., Seiford, L.M. and Zhu, J., Handbook on Data Envelopment Analysis, Springer, 2004

Cullinane, K. and Wang, T.-F. (2006) "The efficiency of European container ports: A cross-sectional data envelopment analysis", International Journal of Logistics Research and Applications, 9, 1, 19-31

Cullinane, K., Wang, T.-F., Song, D.-W., Ji, P. (2006) "The technical efficiency of container ports: Comparing data envelopment analysis and stochastic frontier analysis", Transportation Research Part A, 40, 4, 354-374

Cullinane, K. and Wang, T. (2010) "The efficiency analysis of container port production using DEA panel data approaches", OR Spectrum, 32, 3, 717-738

Estache, A., Tovar de la Fé, B. and Trujillo, L. (2004) "Sources of efficiency gains in port reform: a DEA decomposition of a Malmquist TFP index for Mexico”, Utilities Policy, 12, $221-230$

Estelle, S.M., Johnson, A.L. and Ruggiero, J. (2010) “Three-stage DEA models for incorporating exogenous inputs", Computers and Operations Research, 37, 1087-1090

Gadhia, H.K., Kotzab, H., Prockl, G. (2011) "Levels of internationalization in the container shipping industry: an assessment of the port networks of the large container shipping companies", Journal of Transport Geography, 149, 1431-1442

González-Torre, P., Sarkis, J., Adenso-Díaz, B. (2013) "Shipping agents and container management: an exploratory analysis of infrastructural and cost concerns", International Journal of Shipping and Transport Logistics, 5:3, 322-349 
Guironnet, J.P., Peypoch, N. and Solonandrasana, B. (2009) “A note on productivity change in French and Italian seaports", International Journal of Shipping and Transport Logistics, 1, 3, 216-226

Gutiérrez, E., Lozano, S. and Furió, S. (2014) "Evaluating efficiency of international container shipping lines: A bootstrap DEA approach”, Maritime Economics \& Logistics, $16,55-71$

Haralambides, H., Hussain, M., Barros, C.P. and Peypoch, N. (2010) “A New Approach in Benchmarking Seaport Efficiency and Technological Change”, International Journal of Transport Economics, 37, 1, 20-22

Hoff, A. (2007) "Second stage DEA: Comparison of approaches for modelling the DEA score”, European Journal of Operational Research, 181, 425-435

Hung, S.W., Lu, W.M. and Wang, T.P. (2010) "Benchmarking the operating efficiency of Asia container ports”, European Journal of Operational Research, 203, 706-713

Hwang, N.S. and Kao, T.L. (2008) "Using two-stage DEA to measure managerial efficiency change of non-life insurance companies in Taiwan", International Journal of Management and Decision Making, 9, 4, 377-401

Kamble, S.S., Raoot, A.D. and Khanapuri, V.B. (2010) "Improving port efficiency: a comparative study of selected ports in India", International Journal of Shipping and Transport Logistics, 2, 4, 444-470

Lansink, A.O. and Reinhart, S. (2004) "Investigating technical efficiency and potential technological change in Dutch pig farming”, Agricultural Systems, 79, 353-367 
Lin, L.C. and Tseng, C.C. (2007) "Operational performance evaluation of major container ports in the Asia-Pacific region", Maritime Policy and Management, 34, 6, 535-551

Lozano, S. (2009) "Estimating productivity growth of Spanish ports using a non-radial, non-oriented Malmquist index”, International Journal of Shipping and Transport Logistics, $1,3,227-248$

Lozano, S., Villa, G. and Canca, D. (2011) “Application of Centralised DEA Approach to Capital Budgeting in Spanish Ports", Computers and Industrial Engineering, 60, 455-465

Managi, S. (2007) "Maritime Shipping Industry and Productivity in Japan", Maritime Economics and Logistics, 9, 291-301

Mangan, J., Lalwani, C. and Smurfit, M. (2008) "Port-centric logistics", Journal of Logistics Management, 19, 1, 29-41

McDonald, J. (2009) "Using least squares and tobit in second stage DEA efficiency analysis", European Journal of Operational Research, 197, 792-798

Notteboom, T., Coeck, C. and van den Broeck, J. (2000) "Measuring and explaining the relative efficiency of container terminals by means of Bayesian stochastic frontier models", International Journal of Maritime Economics, 2, 83-106

Pallis A.A. and Syriopoulos, T. (2007) "Port governance models: Financial evaluation of Greek port restructuring”, Transport Policy, 14, 3, 232-246

Pallis, A.A., Vitsounis, T.K. and de Langen, P.W. (2010) "Port economies, policy and management: review of an emerging research field", Transport Reviews, 30, 1, 115-161 
Papke, L.E. and Wooldridge, J.M. (1996) "Econometric methods for fractional response variables with an application to $401(\mathrm{k})$ plan participation rates", Journal of Applied Econometrics, 11, 6, 619-632

Pettit, S.J. and Beresford, A.K.C. (2009) "Port development: from gateways to logistics hubs", Maritime Policy \& Management, 36, 3, 253-267

Rios, L.R. and Maçada, A.C.G. (2006) "Analysing the Relative Efficiency of Container Terminals of Mercosur using DEA”, Maritime Economics and Logistics, 8, 331-346

Saeed, N. (2009) “An analysis of carriers' selection criteria when choosing container terminals in Pakistan”, Maritime Economics and Logistics, 11, 270-288.

Simar, L. and Wilson, P.W. (2007) "Estimation and inference in two stage, semi-parametric models of productive efficiency", Journal of Econometrics, 136, 31-64

Sun, J. and Yang, Z. (2006) "Analysis on the synthetical application of empty container distributing and leasing and leasing strategy", in Proceedings of the Fifth International Conference on Machine Learning and Cybernetics, Dalian

Thai, V.V. (2012) "Competencies required by port personnel in the new era: conceptual framework and case study", International Journal of Shipping and Transport Logistics, 4, $1,49-77$

Thanassoulis, E., Introduction to the Theory and Application of Data Envelopment Analysis: A Foundation Text with Integrated Software, Kluwer Academic Publishers, Norwell, MA, 2001 
Tongzon, J. (2001) "Efficiency measurement of selected Australian and other international ports using data envelopment analysis", Transportation Research A: Policy and Practice, $35,2,107-122$

Yeh, C.P., Wang, K.M. and Chai, K.C. (2010) "Measuring the efficiency of securities companies by corporate governance in a financial holding and non-financial holding system”, Expert System with Applications, 37, 4671-4679

Wang, T.F., Cullinane, K. and Song, D.W. (2005) Container port production and economic efficiency, Palgrave-Macmillan, Basingstoke

Wang, T.F. and Cullinane, K. (2006) "The Efficiency of European Container Terminals and Implications for Supply Chain Management”, Maritime Economics and Logistics, 8, 82-99

Wang, S. and Meng, Q. (2012) "Liner ship fleet deployment with container transhipment operations", Transportation Research Part E, vol.48, pp.470-484

Wu, Y.C.J. and Goh, M. (2010) "Container port efficiency in emerging and more advanced markets", Transportation Research Part E, 46, 6, 1030-1042

Zhu, J., Quantitative Models for Performance Evaluation and Benchmarking: Data Envelopment Analysis with Spreadsheets and DEA Excel Solver, Springer, Heidelberg, 2002 


\section{List of figures and table captions}

Figure 1. Technical efficiency by port

Table 1. Database of Spanish shipping agents: inputs and outputs

Table 2. Technical and scale efficiency, returns to scale and slacks

Table 3. Iterations of the outlier detection method

Table 4. Database of Spanish shipping agents: exogenous variables

Table 5. Regression models specification

Table 6. Second-stage results using OLS, QMLE and TBR 


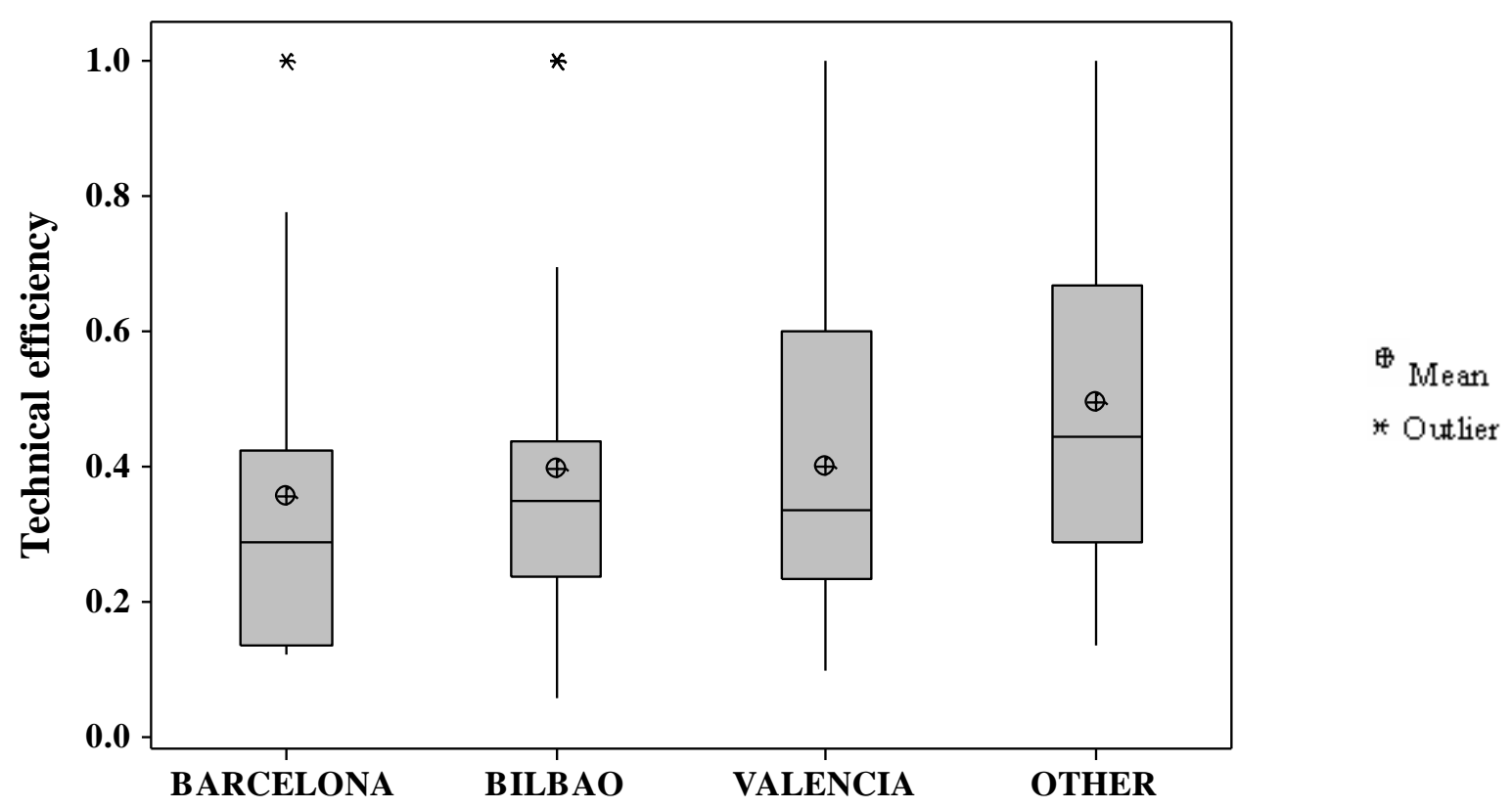

Note: Based on 77 observations

Figure 1. Technical efficiency by port 


\begin{tabular}{|c|c|c|c|}
\hline ID & \# employees & Loaded cont. & Empty cont. \\
\hline 1 & 14 & 10000 & 1700 \\
\hline 2 & 43 & 7000 & 4500 \\
\hline 3 & 30 & 18000 & 7000 \\
\hline 4 & 12 & 500 & 2000 \\
\hline 5 & 9 & 1200 & 7000 \\
\hline 6 & 12 & 2000 & 780 \\
\hline 7 & 3 & 1000 & 0 \\
\hline 8 & 6 & 2050 & 0 \\
\hline 9 & 30 & 57000 & 0 \\
\hline 10 & 18 & 20000 & 5000 \\
\hline 11 & 2 & 520 & 7800 \\
\hline 12 & 10 & 1500 & 2500 \\
\hline 13 & 35 & 25000 & 18000 \\
\hline 14 & 3 & 800 & 0 \\
\hline 15 & 18 & 150 & 1850 \\
\hline 16 & 6 & 3000 & 0 \\
\hline 17 & 48 & 5760 & 9600 \\
\hline 18 & 6 & 2904 & 20 \\
\hline 19 & 9 & 8552 & 360 \\
\hline 20 & 20 & 2000 & 6000 \\
\hline 21 & 13 & 22000 & 0 \\
\hline 22 & 21 & 500 & 1900 \\
\hline 23 & 13 & 1000 & 16000 \\
\hline 24 & 14 & 2500 & 0 \\
\hline 25 & 22 & 15000 & 0 \\
\hline 26 & 7 & 1110 & 1820 \\
\hline 27 & 4 & 1400 & 500 \\
\hline 28 & 30 & 50 & 1250 \\
\hline 29 & 10 & 150 & 1200 \\
\hline 30 & 13 & 950 & 29050 \\
\hline 31 & 23 & 24000 & 1500 \\
\hline 32 & 9 & 3500 & 2000 \\
\hline 33 & 6 & 1200 & 0 \\
\hline 34 & 23 & 9000 & 25000 \\
\hline 35 & 7 & 10724 & 8900 \\
\hline 36 & 9 & 3300 & 0 \\
\hline 37 & 10 & 800 & 0 \\
\hline 38 & 3 & 540 & 0 \\
\hline 39 & 32 & 33343 & 3372 \\
\hline 40 & 35 & 15000 & 0 \\
\hline 41 & 9 & 4116 & 0 \\
\hline 42 & 12 & 13428 & 0 \\
\hline 43 & 50 & 7258 & 15901 \\
\hline
\end{tabular}

\begin{tabular}{|c|c|c|c|}
\hline 44 & 70 & 120 & 0 \\
\hline 45 & 9 & 3800 & 200 \\
\hline 46 & 16 & 7500 & 0 \\
\hline 47 & 6 & 1000 & 1000 \\
\hline 48 & 11 & 4400 & 300 \\
\hline 49 & 1 & 100 & 0 \\
\hline 50 & 13 & 3000 & 3000 \\
\hline 51 & 14 & 4000 & 120 \\
\hline 52 & 12 & 5000 & 0 \\
\hline 53 & 6 & 470 & 2590 \\
\hline 54 & 15 & 4800 & 0 \\
\hline 55 & 45 & 5450 & 0 \\
\hline 56 & 12 & 3000 & 1000 \\
\hline 57 & 4 & 600 & 0 \\
\hline 58 & 10 & 6989 & 0 \\
\hline 59 & 30 & 200 & 0 \\
\hline 60 & 12 & 100000 & 500 \\
\hline 61 & 3 & 1300 & 200 \\
\hline 62 & 12 & 6000 & 1200 \\
\hline 63 & 9 & 3500 & 0 \\
\hline 64 & 21 & 1500 & 2500 \\
\hline 65 & 26 & 20823 & 18569 \\
\hline 66 & 40 & 6145 & 3592 \\
\hline 67 & 100 & 75000 & 500 \\
\hline 68 & 4 & 10000 & 0 \\
\hline 69 & 210 & 267000 & 128300 \\
\hline 70 & 18 & 2600 & 5000 \\
\hline 71 & 20 & 18000 & 4500 \\
\hline 72 & 9 & 3120 & 4860 \\
\hline 73 & 9 & 2200 & 6000 \\
\hline 74 & 10 & 4376 & 365 \\
\hline 75 & 7 & 1000 & 1050 \\
\hline 76 & 6 & 54013 & 20863 \\
\hline 77 & 14 & 2000 & 10000 \\
\hline 78 & 49 & 25100 & 5100 \\
\hline 79 & 4 & 150 & 60 \\
\hline 80 & 30 & 12000 & 6000 \\
\hline 81 & 52 & 17000 & 5000 \\
\hline 82 & 5 & 100 & 1600 \\
\hline 83 & 11 & 1020 & 0 \\
\hline 84 & 7 & 2500 & 0 \\
\hline 85 & 3 & 5200 & 800 \\
\hline
\end{tabular}

Table 1. Database of Spanish shipping agents: inputs and outputs.

Source: González et al (2013) 


\begin{tabular}{|c|c|c|c|c|c|c|}
\hline ID & T.Eff. & T.Eff.' & S. Eff. & RTS & LC slack & EC slack \\
\hline 1 & 0.137 & 0.326 & 0.423 & IRS & 0 & 0 \\
\hline 2 & 0.043 & 0.125 & 0.526 & IRS & 0 & 0 \\
\hline 3 & 0.089 & 0.234 & 0.746 & IRS & 0 & 0 \\
\hline 4 & 0.106 & 0.373 & 0.212 & IRS & 876 & 0 \\
\hline 5 & 0.214 & 0.672 & 0.537 & IRS & 98 & 0 \\
\hline 6 & 0.098 & 0.342 & 0.142 & IRS & 0 & 0 \\
\hline 7 & 0.361 & - & - & - & - & - \\
\hline 8 & 0.197 & 0.667 & 0.062 & IRS & 7950 & 0 \\
\hline 9 & 0.213 & 0.273 & 0.836 & IRS & 0 & 261 \\
\hline 10 & 0.158 & 0.362 & 0.701 & IRS & 0 & 0 \\
\hline 11 & 1.000 & - & - & - & - & - \\
\hline 12 & 0.138 & 0.463 & 0.278 & IRS & 0 & 0 \\
\hline 13 & 0.146 & 0.324 & 0.963 & IRS & 0 & 0 \\
\hline 14 & 0.355 & - & - & - & - & - \\
\hline 15 & 0.069 & 0.246 & 0.189 & IRS & 1229 & 0 \\
\hline 16 & 0.211 & 0.667 & 0.090 & IRS & 7000 & 0 \\
\hline 17 & 0.053 & 0.145 & 0.710 & IRS & 0 & 0 \\
\hline 18 & 0.210 & 0.667 & 0.088 & IRS & 6752 & 0 \\
\hline 19 & 0.198 & 0.454 & 0.286 & IRS & 0 & 0 \\
\hline 20 & 0.092 & 0.287 & 0.504 & IRS & 0 & 0 \\
\hline 21 & 0.233 & 0.390 & 0.521 & IRS & 0 & 67 \\
\hline 22 & 0.060 & 0.211 & 0.203 & IRS & 878 & 0 \\
\hline 23 & 0.347 & 0.684 & 0.812 & IRS & 156 & 0 \\
\hline 24 & 0.087 & 0.286 & 0.075 & IRS & 7500 & 0 \\
\hline 25 & 0.108 & 0.202 & 0.405 & IRS & 0 & 28 \\
\hline 26 & 0.182 & 0.631 & 0.212 & IRS & 269 & 0 \\
\hline 27 & 0.280 & 1.000 & 0.097 & IRS & $\mathbf{0}$ & $\mathbf{0}$ \\
\hline 28 & 0.039 & 0.141 & 0.132 & IRS & 1338 & 0 \\
\hline 29 & 0.115 & 0.422 & 0.130 & IRS & 1239 & 0 \\
\hline 30 & 1.000 & 1.000 & 1.000 & CRS & 0 & 0 \\
\hline 31 & 0.140 & 0.248 & 0.611 & IRS & 0 & 0 \\
\hline 32 & 0.156 & 0.501 & 0.288 & IRS & 0 & 0 \\
\hline 33 & 0.184 & 0.667 & 0.036 & IRS & 8800 & 0 \\
\hline 34 & 0.415 & 0.536 & 0.986 & IRS & 0 & 0 \\
\hline 35 & 0.370 & 1.000 & 0.745 & IRS & $\mathbf{0}$ & $\mathbf{0}$ \\
\hline 36 & 0.144 & 0.444 & 0.099 & IRS & 6700 & 0 \\
\hline 37 & 0.106 & 0.400 & 0.024 & IRS & 9200 & 0 \\
\hline 38 & 0.347 & - & - & - & - & - \\
\hline 39 & 0.128 & 0.223 & 0.759 & IRS & 0 & 0 \\
\hline 40 & 0.068 & 0.127 & 0.405 & IRS & 0 & 28 \\
\hline 41 & 0.152 & 0.444 & 0.123 & IRS & 5884 & 0 \\
\hline 42 & 0.186 & 0.359 & 0.374 & IRS & 0 & 19 \\
\hline 43 & 0.090 & 0.182 & 0.871 & IRS & 0 & 0 \\
\hline
\end{tabular}

\begin{tabular}{|c|c|c|c|c|c|c|}
\hline 44 & 0.014 & 0.057 & 0.004 & IRS & 9880 & 0 \\
\hline 45 & 0.149 & 0.444 & 0.134 & IRS & 2760 & 0 \\
\hline 46 & 0.105 & 0.250 & 0.225 & IRS & 2500 & 0 \\
\hline 47 & 0.194 & 0.693 & 0.135 & IRS & 392 & 0 \\
\hline 48 & 0.127 & 0.364 & 0.163 & IRS & 440 & 0 \\
\hline 49 & 1.000 & - & - & - & - & - \\
\hline 50 & 0.116 & 0.371 & 0.350 & IRS & 0 & 0 \\
\hline 51 & 0.097 & 0.286 & 0.131 & IRS & 3936 & 0 \\
\hline 52 & 0.121 & 0.333 & 0.150 & IRS & 5000 & 0 \\
\hline 53 & 0.224 & 0.776 & 0.259 & IRS & 897 & 0 \\
\hline 54 & 0.096 & 0.267 & 0.144 & IRS & 5200 & 0 \\
\hline 55 & 0.033 & 0.089 & 0.164 & IRS & 4550 & 0 \\
\hline 56 & 0.106 & 0.349 & 0.190 & IRS & 0 & 0 \\
\hline 57 & 0.262 & 1.000 & 0.018 & IRS & 9400 & 0 \\
\hline 58 & 0.164 & 0.400 & 0.210 & IRS & 3011 & 0 \\
\hline 59 & 0.034 & 0.133 & 0.006 & IRS & 9800 & 0 \\
\hline 60 & 1.000 & 1.000 & 1.000 & $C R S$ & 0 & 0 \\
\hline 61 & 0.370 & - & - & - & - & - \\
\hline 62 & 0.129 & 0.359 & 0.288 & IRS & 0 & 0 \\
\hline 63 & 0.146 & 0.444 & 0.105 & IRS & 6500 & 0 \\
\hline 64 & 0.066 & 0.221 & 0.278 & IRS & 0 & 0 \\
\hline 65 & 0.204 & 0.430 & 0.956 & IRS & 0 & 0 \\
\hline 66 & 0.043 & 0.127 & 0.458 & IRS & 0 & 0 \\
\hline 67 & 0.087 & 0.098 & 0.922 & IRS & 0 & 0 \\
\hline 68 & 0.480 & 1.000 & 0.300 & IRS & $\mathbf{0}$ & 0 \\
\hline 69 & 1.000 & 1.000 & 0.421 & DRS & $\mathbf{0}$ & $\mathbf{0}$ \\
\hline 70 & 0.097 & 0.302 & 0.464 & IRS & 0 & 0 \\
\hline 71 & 0.133 & 0.309 & 0.666 & IRS & 0 & 0 \\
\hline 72 & 0.194 & 0.601 & 0.467 & IRS & 0 & 0 \\
\hline 73 & 0.205 & 0.639 & 0.508 & IRS & 0 & 0 \\
\hline 74 & 0.140 & 0.401 & 0.169 & IRS & 0 & 0 \\
\hline 75 & 0.167 & 0.596 & 0.140 & IRS & 391 & 0 \\
\hline 76 & 1.000 & - & - & - & - & - \\
\hline 77 & 0.191 & 0.501 & 0.667 & IRS & 0 & 0 \\
\hline 78 & 0.068 & 0.143 & 0.746 & IRS & 0 & 0 \\
\hline 79 & 0.252 & 1.000 & 0.011 & IRS & 8818 & $\mathbf{0}$ \\
\hline 80 & 0.076 & 0.205 & 0.662 & IRS & 0 & 0 \\
\hline 81 & 0.049 & 0.120 & 0.674 & IRS & 0 & 0 \\
\hline 82 & 0.241 & 0.869 & 0.166 & IRS & 1283 & 0 \\
\hline 83 & 0.099 & 0.364 & 0.031 & IRS & 8980 & 0 \\
\hline 84 & 0.175 & 0.571 & 0.075 & IRS & 7500 & 0 \\
\hline 85 & 0.491 & - & - & - & - & - \\
\hline
\end{tabular}

Table 2. Technical and scale efficiency, RTS and slacks. Note: T. Eff: Technical Efficiency based on 85 observ.; T. Eff': Techical Efficiency based on 77 observ., S. Eff: Scale Efficiency; RTS: Returns To Scale 


\begin{tabular}{|c|c|c|c|c|}
\hline Iteration & No. of DMUs & $\begin{array}{c}\text { Removed } \\
\text { DMU }\end{array}$ & $\lambda-\operatorname{sum}$ & $\lambda-\mathrm{count}$ \\
\hline 1 & 85 & 49 & 56.408 & 71 \\
\hline 2 & 84 & 11 & 66.870 & 77 \\
\hline 3 & 83 & 85 & 51.773 & 69 \\
\hline 4 & 82 & 61 & 56.645 & 73 \\
\hline 5 & 81 & 7 & 49.959 & 61 \\
\hline 6 & 80 & 76 & 16.713 & 71 \\
\hline 7 & 79 & 14 & 55.382 & 72 \\
\hline 8 & 78 & 38 & 61.523 & 75 \\
\hline 9 & 77 & $\operatorname{Max}$ & 34.587 & 53 \\
\hline
\end{tabular}

Table 3. Iterations of the outlier detection method 


\begin{tabular}{|c|c|c|c|c|}
\hline ID & Port & ShipComp & ShipLines & Cluster \\
\hline 1 & Valencia & 1 & 1 & 1 \\
\hline 2 & Valencia & 3 & 6 & 2 \\
\hline 3 & Valencia & 4 & 5 & 2 \\
\hline 4 & Valencia & 3 & 3 & 2 \\
\hline 5 & Valencia & 3 & 3 & 2 \\
\hline 6 & Valencia & 3 & 3 & 2 \\
\hline 7 & Vigo & 1 & 1 & 2 \\
\hline 8 & Melilla & 4 & 1 & 1 \\
\hline 9 & Barcelona & 1 & 2 & 3 \\
\hline 10 & Barcelona & 3 & 3 & 3 \\
\hline 11 & Gijon & 2 & 2 & 2 \\
\hline 12 & Valencia & 1 & 1 & 3 \\
\hline 13 & Valencia & 12 & 12 & 1 \\
\hline 14 & Vigo & 3 & 3 & 1 \\
\hline 15 & Cartagena & 3 & 2 & 4 \\
\hline 16 & Cadiz & 2 & 1 & 1 \\
\hline 17 & Cartagena & 1 & 1 & 1 \\
\hline 18 & Algeciras & 1 & 2 & 1 \\
\hline 19 & Barcelona & 4 & 4 & 1 \\
\hline 20 & Barcelona & 5 & 5 & 1 \\
\hline 21 & Barcelona & 1 & 2 & 1 \\
\hline 22 & Cartagena & 1 & 1 & 4 \\
\hline 23 & Alicante & 1 & 3 & 3 \\
\hline 24 & Tenerife & 4 & 1 & 1 \\
\hline 25 & Barcelona & 1 & 4 & 1 \\
\hline 26 & Cadiz & 1 & 15 & 1 \\
\hline 27 & Algeciras & 1 & 1 & 2 \\
\hline 28 & Barcelona & 1 & 1 & - \\
\hline 29 & Cadiz & 1 & 1 & 2 \\
\hline 30 & Vigo & 1 & 2 & 3 \\
\hline 31 & Vigo & 1 & 1 & 3 \\
\hline 32 & Vigo & 6 & 6 & 1 \\
\hline 33 & S.C.Tenerife & 1 & 1 & 2 \\
\hline 34 & Sevilla & 1 & 2 & 2 \\
\hline 35 & Gijón & 3 & 5 & - \\
\hline 36 & Vigo & 2 & 2 & 1 \\
\hline 37 & Alicante & 4 & 4 & 4 \\
\hline 38 & Algeciras & 1 & 3 & 1 \\
\hline 39 & Valencia & 1 & 2 & 1 \\
\hline 40 & Barcelona & 2 & 2 & 1 \\
\hline 41 & Las Palmas & 2 & 3 & 4 \\
\hline 42 & Barcelona & 1 & 1 & 1 \\
\hline
\end{tabular}

\begin{tabular}{|c|c|c|c|c|}
\hline 43 & Marin & 8 & 9 & 1 \\
\hline 44 & Bilbao & 3 & 3 & 2 \\
\hline 45 & Bilbao & 1 & 1 & 4 \\
\hline 46 & Bilbao & 1 & 15 & 2 \\
\hline 47 & Bilbao & 1 & 2 & 2 \\
\hline 48 & Bilbao & 3 & 3 & - \\
\hline 49 & Bilbao & 1 & 4 & 1 \\
\hline 50 & Bilbao & 4 & 4 & 4 \\
\hline 51 & Bilbao & 2 & 5 & 4 \\
\hline 52 & Bilbao & 1 & 7 & 1 \\
\hline 53 & Barcelona & 2 & 2 & 1 \\
\hline 54 & Bilbao & 3 & 2 & 4 \\
\hline 55 & Bilbao & 2 & 2 & 4 \\
\hline 56 & Bilbao & 2 & 2 & - \\
\hline 57 & Bilbao & 2 & 2 & - \\
\hline 58 & Melilla & 2 & 1 & 1 \\
\hline 59 & S.C.Tenerife & 1 & 6 & 4 \\
\hline 60 & Bilbao & 1 & 1 & 3 \\
\hline 61 & Vigo & 1 & 1 & 1 \\
\hline 62 & Bilbao & 1 & 3 & 4 \\
\hline 63 & Tenerife & 3 & 3 & 1 \\
\hline 64 & Bilbao & 5 & 5 & 4 \\
\hline 65 & Bilbao & 1 & 2 & 3 \\
\hline 66 & Barcelona & 3 & 3 & 3 \\
\hline 67 & Valencia & 6 & 7 & 1 \\
\hline 68 & Las Palmas & 1 & 46 & - \\
\hline 69 & Valencia & 1 & 18 & 2 \\
\hline 70 & Valencia & 2 & 2 & 4 \\
\hline 71 & Valencia & 1 & 2 & 1 \\
\hline 72 & Valencia & 3 & 3 & 2 \\
\hline 73 & Valencia & 1 & 2 & 2 \\
\hline 74 & Valencia & 1 & 1 & 1 \\
\hline 75 & Valencia & 1 & 1 & 2 \\
\hline 76 & Vigo & 2 & 2 & 3 \\
\hline 77 & Cadiz & 1 & 1 & 1 \\
\hline 78 & Valencia & 1 & 3 & 1 \\
\hline 79 & Barcelona & 1 & 1 & 2 \\
\hline 80 & Bilbao & 2 & 2 & 1 \\
\hline 81 & Barcelona & 1 & 4 & 1 \\
\hline 82 & Tarragona & 1 & 1 & 2 \\
\hline 83 & Vigo & 2 & 2 & 1 \\
\hline 84 & Tenerife & 1 & 3 & 1 \\
\hline 85 & Valencia & 1 & 2 & 1 \\
\hline
\end{tabular}




\begin{tabular}{|c|c|}
\hline$\#$ & Model Specification \\
\hline$(1)$ & $E \ln ($ Efficiency $) / x=\beta_{0}+\beta_{1}$ Valencia $+\beta_{2}$ Barcelona $+\beta_{3}$ Bilbao $+\beta_{4}$ ShipComp $+\beta_{5}$ ShipLines $+\beta_{6} C 1+\beta_{7} C 2+\beta_{8} C 3$ \\
\hline$(2)$ & $E$ Efficiency $/ x=G \beta_{0}+\beta_{1}$ Valencia $+\beta_{2}$ Barcelona $+\beta_{3}$ Bilbao $+\beta_{4}$ ShipComp $+\beta_{5}$ ShipLines $+\beta_{6} C 1+\beta_{7} C 2+\beta_{8} C 3$ \\
\hline$(3)$ & $E$ Efficiency $/ x=\beta_{0}+\beta_{1}$ Valencia $+\beta_{2}$ Barcelona $+\beta_{3}$ Bilbao $+\beta_{4}$ ShipComp $+\beta_{5}$ ShipLines $+\beta_{6} C 1+\beta_{7} C 2+\beta_{8} C 3$ \\
\hline
\end{tabular}

Note: $G(z)=\frac{\exp (z)}{1+\exp (z)}$

Table 5. Regression models specification 


\begin{tabular}{|c|c|c|c|}
\hline & OLS & QMLE & TBR \\
\hline Model & (1) & (2) & (3) \\
\hline Intercept & $\begin{array}{r}-1.4193 * * \\
(0.3657)\end{array}$ & $\begin{array}{c}-1.1602 * \\
(0.5285)\end{array}$ & $\begin{array}{c}-0.1052 \\
(0.0657)\end{array}$ \\
\hline Barcelona & $\begin{array}{r}-0.2168 \\
(0.2301)\end{array}$ & $\begin{array}{r}-0.2334 \\
(0.3813)\end{array}$ & $\begin{array}{l}-0.1145 \\
(0.0991)\end{array}$ \\
\hline Bilbao & $\begin{array}{r}-0.3175 \\
(0.2411)\end{array}$ & $\begin{array}{r}-0.4209 \\
(0.3526)\end{array}$ & $\begin{array}{c}-0.0012 \\
(0.0172)\end{array}$ \\
\hline Valencia & $\begin{array}{r}-0.1898 \\
(0.1569)\end{array}$ & $\begin{array}{r}-0.3091 \\
(0.2386)\end{array}$ & $\begin{array}{c}-0.0679 \\
(0.0967)\end{array}$ \\
\hline ShipComp & $\begin{array}{r}-0.0396 \\
(0.0375)\end{array}$ & $\begin{array}{r}-0.0835 \\
(0.0514)\end{array}$ & $\begin{array}{l}-0.1269 \\
(0.0220)\end{array}$ \\
\hline ShipLines & $\begin{array}{r}0.0594 * \\
(0.0292) \\
\end{array}$ & $\begin{array}{c}0.1255^{*} \\
(0.0604) \\
\end{array}$ & $\begin{array}{l}0.0321 * \\
(0.1399)\end{array}$ \\
\hline$C 1$ & $\begin{array}{c}0.7510^{*} \\
(0.3201)\end{array}$ & $\begin{array}{r}1.4143 * * \\
(0.4934)\end{array}$ & $\begin{array}{l}0.3627^{*} \\
(0.1100)\end{array}$ \\
\hline$C 2$ & $\begin{array}{c}0.4971 * \\
(0.2854)\end{array}$ & $\begin{array}{r}0.9409 * * \\
(0.3959)\end{array}$ & $\begin{array}{l}0.2296 * \\
(0.0951)\end{array}$ \\
\hline C3 & $\begin{array}{c}0.3765^{*} \\
(0.3084)\end{array}$ & $\begin{array}{c}0.7803 * \\
(0.3643)\end{array}$ & $\begin{array}{l}0.2033 * \\
(0.1567)\end{array}$ \\
\hline $\begin{array}{l}\text { Robust } \\
\text { RESET statistic } \\
\text { [p-value] }\end{array}$ & $\begin{array}{r}2.80 \\
{[0.2455]}\end{array}$ & $\begin{array}{r}2.69 \\
{[0.2611]}\end{array}$ & - \\
\hline Log-Likelihood & -60.7077 & -33.6980 & -3.0577 \\
\hline
\end{tabular}

Notes:

Figures in parentheses are the estimated standard errors of the regression coefficients

Based on 71 observations

OLS: Ordinary Least Squares; QMLE: Quasi-Maximum Likelihood Estimator; TBR: Truncated Bootstrapped Regression (total number of replications: 2000)

* significant at $5 \%$ level; ** significant at $1 \%$ level

F ratio model $(1)=2.0319^{*}$

$\hat{\sigma}_{\varepsilon} \operatorname{model}(3): 0.0199^{* *}$

Table 6. Second-stage results using OLS, QMLE and TBR 